Document downloaded from:

http://hdl.handle.net/10251/65316

This paper must be cited as:

Nácher Soler, VE.; Jaén Martínez, FJ.; Catalá Bolós, A. (2014). Exploring Visual Cues for Intuitive Communicability of Touch Gestures to Pre-kindergarten Children. 9th ACM International Conference on Interactive Tabletops and Surfaces (ACM ITS 2014). ACM. doi:10.1145/2669485.2669523.

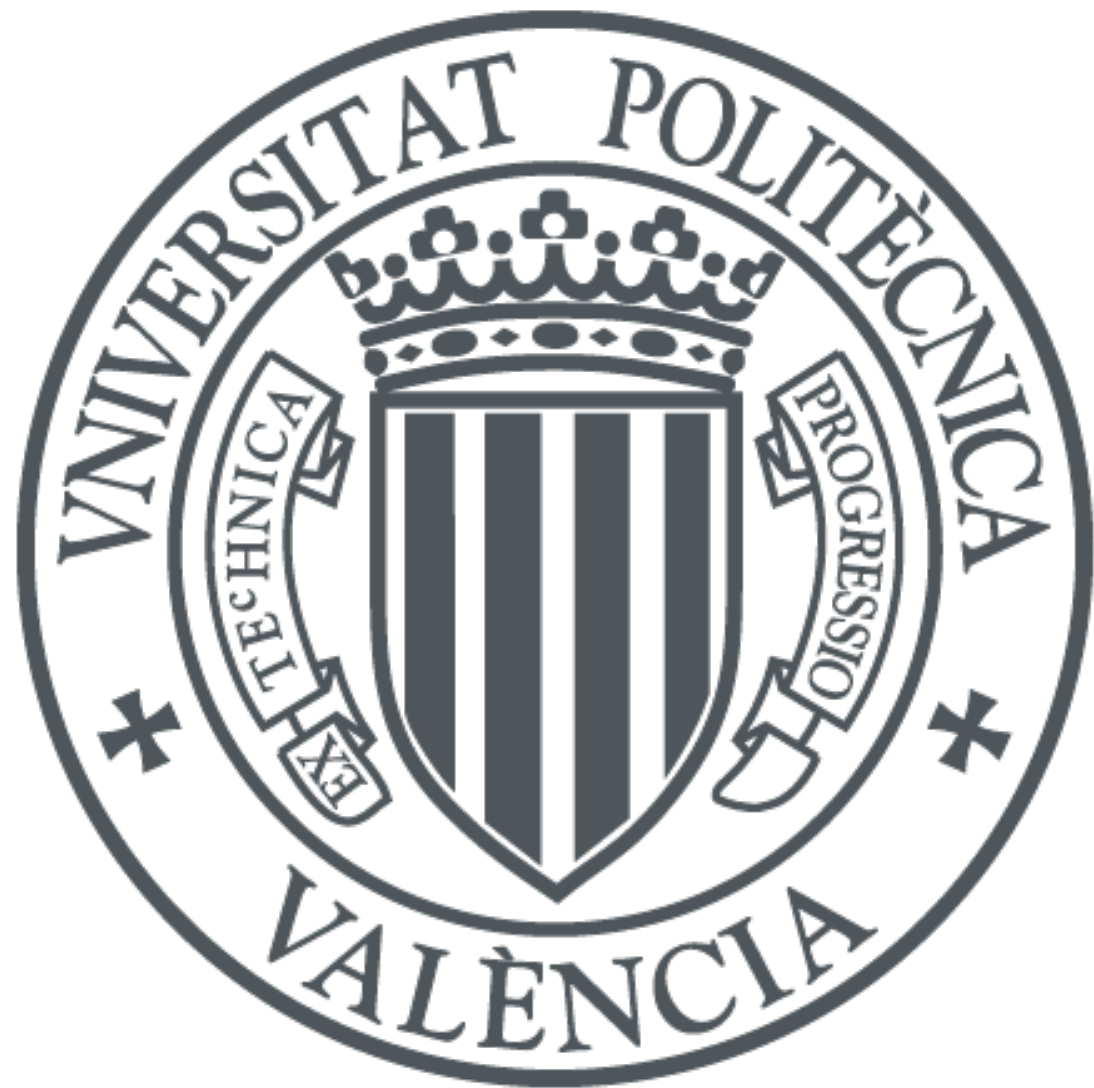

The final publication is available at

http://dl.acm.org/citation.cfm?id=2669523

Copyright ACM

Additional Information

(C) ACM, 2014. This is the author's version of the work. It is posted here by permission of ACM for your personal use. Not for redistribution. The definitive version was published in ACM In Proceedings of the Ninth ACM International Conference on Interactive Tabletops and Surfaces (pp. 159-162). http://doi.acm.org/10.1145/2669485.2669523 


\title{
Exploring Visual Cues for Intuitive Communicability of Touch Gestures to Pre-kindergarten Children
}

\author{
Vicente Nacher, Javier Jaen, Alejandro Catala \\ ISSI Group, Dpto. Sistemas Informáticos y Computación, Universitat Politècnica de València. \\ \{vnacher, fjaen, acatala\}@dsic.upv.es
}

\begin{abstract}
Pre-kindergarten children are becoming frequent users of multi-touch technology and, according to previous studies they are able to perform several multi-touch gestures successfully. However, they do not use these devices supervised at all times. Consequently, interactive applications for pre-kindergarteners need to convey their underlying design intent and interactive principles with respect to touch interaction. In this paper, we present and evaluate two approaches to communicate three different touch gestures (tap, drag and scale up) to pre-kindergarten users. Our results show, firstly, that it is possible to effectively communicate them using visual cues and, secondly, that an animated semiotic approach is better than an iconic one.
\end{abstract}

\section{Author Keywords}

Touch interaction; Communicability; pre-kindergarten

\section{ACM Classification Keywords}

H.5.2. [Information interfaces and presentation]: User Interfaces - Evaluation/methodology, Interaction Styles

\section{INTRODUCTION}

Recent studies [10] have revealed that very young children are frequent users of multi-touch devices. In fact, children encounter touch technology often before they can even speak, they do not use these devices supervised at all times and they often want to do things on their own, instead of having their parents show them. Moreover, recent work [7] has also revealed that children between the ages of two and four are able to perform a wider set of touch gestures than those typically used in commercial learning applications (tap and drag). In this context, a key challenge to address is the efficient and effective communication of the gestures that are expected at a given moment from these very young users, i.e., languages need to be designed for applications to convey their underlying design intent and interactive

\footnotetext{
Permission to make digital or hard copies of all or part of this work for personal or classroom use is granted without fee provided that copies are not made or distributed for profit or commercial advantage and that copies bear this notice and the full citation on the first page. Copyrights for components of this work owned by others than ACM must be honored. Abstracting with credit is permitted. To copy otherwise, or republish, to post on servers or to redistribute to lists, requires prior specific permission and/or a fee. Request permissions from permissions@acm.org.

ITS 2014, November 16-19, 2014, Dresden, Germany.

Copyright @ 2014 ACM 978-1-4503-2587-5/14/11...\$15.00.

Add the DOI string from ACM e-form confirmation email.
}

principles [9] with respect to touch interaction. These languages would allow the autonomous interaction of very young children with direct touch applications without the continuous intervention and guidance of adults.

In this paper we perform a communicability evaluation to appreciate how well pre-kindergarten users understand the messages that communicate a given expected touch gesture using two different semiotic systems. The semiotic systems under consideration in this work are of graphical nature because, although it has already been tested that including instructions in the form of short text pieces is adequate for primary school children $[3,8]$, pre-kindergarten users do not have the required abilities to understand text messages.

The obtained results suggest that it is possible to design visual languages for communicating touch gestures for prekindergarten children. The animated approach that is proposed in this work is more effective to communicate dynamic gestures, i.e. gestures that follow trajectories on the screen, in terms of both intuitiveness and potential learnability.

\section{RELATED WORK}

The problem of communicability has received recently a great deal of attention in the context of applications for adults $[2,11]$. Moreover, several works have studied the way in which instructions are given in applications for children. The work in [3] explored different ways to provide instructions in applications targeted at 5-6 year old children in desktop computers. This study resulted in some design recommendations such as giving visual cues to trigger attention to find new content, providing help in the form of text adapted to such target users, and providing separate video instructions so that children can focus on the explanation given. This work also found that audio help could overcome some limitations of written instructions like in [8].

Another previous work [1] has proposed a character-based language to communicate multi-touch gestures in a learning application with 5-6 year old children. Researchers associated each gesture to a specific virtual character in the learning application that appeared when a gesture was requested. The characters were chosen in such a way that the gesture was "recallable": a jumping grasshopper for a double tap, a walking ladybug for a drag gesture, a hovering butterfly for a tilting gesture and so on. 
McKnight and Fitton [6] performed an initial test of common touch-screen terminology with native English children aged between 6 and 7. Children had little or no trouble in understanding the majority of the instructions provided in both textual and audio form as they completed the task easily.

These previous works have attempted several semiotic systems consisting of text, audio and/or visual elements for very young children aged 5-7. However, there is no study that explores the more challenging pre-kindergarten age range. Therefore, in this work we explore the communicability of two languages for pre-kindergarten users so that interactive applications can effectively communicate touch gestures.

\section{LANGUAGES OVERVIEW}

In order to adequately select the candidate languages that would be evaluated, a number of workshops took place with pre-kindergarten educators. A summary of the design rationale is described here for the two languages that were selected after this design process with pedagogy experts:

-Animated Hand language: this language uses the metaphor of a hand with one extended finger to simulate by means of an animation the required gesture. The rationale behind this language is that the object to be manipulated with a multitouch interaction is accompanied by an animated virtual hand that provides visual cues about the gesture that should be carried out. We considered several options to visualize the form of a hand in our preliminary designs, and discussed with educators about the suitability of displaying either an isolated finger or an entire hand. Having an isolated finger was discarded and a Mickey Mouse's hand was selected by the educators for the evaluation phase (see Figure 2). For the tap gesture the hand appears and disappears once. For the remaining gestures, the hand(s) follow(s) the expected trajectory that the user's hand(s) should follow when performing the expected gesture (see Figure 2 for animated sequences).

-Iconic language: in this case the semiotic language selected by the educators consists in a static image or icon of a hand with accompanying symbolic arrows describing the expected gesture (see Figure 2). The icons used are extracted from a commercial icon set created to aid in the design, development, implementation and promotion of multi-touch interfaces [4], designed by a professional interactive designer and developer. This iconic language can also be found in Leap Motion applications. It was decided to maintain a naturalistic hand representation to evaluate this widely used commercial icon set in its original form to consider its suitability for pre-K children.

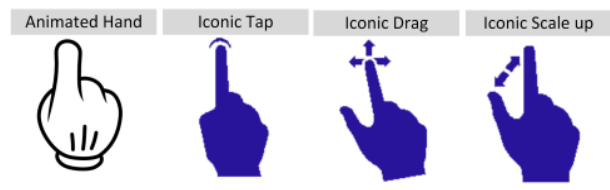

Figure 2. Evaluated semiotic elements.

\section{EXPERIMENTAL STUDY}

The goal of this study is to obtain preliminary results about the effectiveness of two semiotic systems, one based on animations and another based on icon features, to communicate touch gestures to prekindergarten children. In this respect we have considered three categories of gestures: one-hand dynamic interactions, which require movements describing a clear trajectory; bi-manual dynamic interactions, with both hands describing trajectories; or inplace interactions, in which one hand does not actually describe a trajectory but tap at a very specific pace or in a specific way. In each category a representative gesture was selected to perform this first evaluation study: Drag, Scale $U p$ and Tap respectively.

Therefore, the main research questions of this work are formulated as follows:

RQ1: Is any of the considered languages effective in communicating intuitively each of the considered touch gestures to pre-kindergarten children?

RQ2: Is the effectiveness of the communication process improved after a short training process?

RQ3: Is the inherent complexity of tracking several animated hands manageable?

RQ4: Is the effectiveness of the communication process affected by gender?
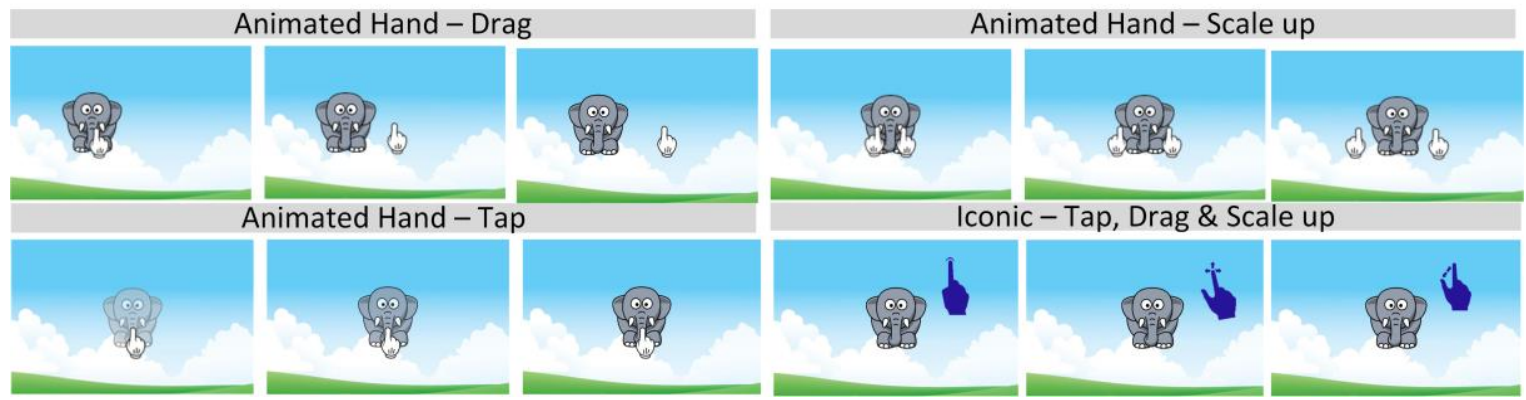

Figure 1. Description of animated visual cues and icons used in the considered gesture subset by language. 


\section{Participants}

Parental authorization was obtained before carrying out the study. Twenty four children aged between twenty-five and thirty-eight months took part in the experiment (Mean (M) $=31.67$, Standard Deviation $(\mathrm{SD})=4.02)$. The minimum age limit was chosen because children are in a preoperational stage from 2 years old onwards. They begin to think in terms of images and symbols, and develop symbolic play with imaginary objects, which means they could be candidates for multi-touch technology at this early age as discussed in [6]. Fourteen participants were female. One group by language was defined.

\section{Apparatus}

The interaction framework for the experiment was implemented in Java using JMonkeyEngine SDK v.3.0beta. The devices used for the experiment were a Motorola MZ601 and a Samsung Galaxy Note 10.1 tablet with Android 3.2 both with capacitive multi-touch screens.

\section{Procedure}

Initially, the experimenter showed each gesture without using any language (i.e. without visual stimuli associated to the gesture) and asked the children to interact to ensure that they were able to perform each gesture. This ensures that the evaluated children had the developmental cognitive and physical abilities to perform the proposed gestures.

After this activity, the participant performed an evaluation test consisting of $2 \times 3=6$ randomized trials (two repetitions of each gesture Tap, Drag and Scale up). In each test trial an image of an animal appeared on the screen (see Figure 2) and a visual stimulus describing the required gesture was displayed. The visual stimulus belonged to the language previously assigned to each subject (see Design). Once it was shown, the system awaited the user interaction without any external adult guidance. If the gesture was successfully completed, the platform gave a positive audiovisual feedback in the form of animated stars and applauses. If the experimenter observed that the participant did not carry out the gesture in less than 10 seconds, it was marked as undone and the child went on to the next trial. The system recorded the number of correct interactions. The goal of this first evaluation phase (Intuitive Phase) was to evaluate the capacity of the language to communicate a gesture without any previous language exposure.

Next, the participants carried out a specific language training activity. This training activity was designed to teach children which gestures are expected to be performed given the visual stimuli provided by the language. It was carried out under the supervision of the experimenter who explained the visual instructions to them and the associated gestures.

Finally, an evaluation test was carried out without delay (Immediate Recall phase). In this way, this phase evaluates the impact on the overall performance of a short training session with the visual languages, i.e., to know whether the inclusion of a short guided tutorial with the proposed visual languages makes children more effective in the subsequent unsupervised interaction.

\section{Design}

Each child was only exposed to one language, which was assigned randomly at the beginning of the session. The success rate (successful interactions/total interactions) by gesture and session in a given language expressed as a percentage was obtained for each participant. This was the dependent variable used in the analysis when searching for differences between the intuitive and immediate recall phases. As data did not meet normality assumptions and given the need to handle repeated measures, the analysis was be carried out by applying the Aligned Rank Transform in order to report using ANOVA with three factors: gender, phase (Intuitive vs. Immediate Recall) and language (Animated Hand vs. Iconic).

\section{RESULTS}

Table 1 shows the mean success rate for each gesture by language, gender and phase.

\begin{tabular}{|c|c|c|c|c|c|c|c|c|}
\cline { 2 - 9 } \multicolumn{1}{c|}{} & \multicolumn{4}{c|}{ Language } & \multicolumn{4}{c|}{ Gender } \\
\cline { 2 - 10 } \multicolumn{1}{c|}{} & \multicolumn{2}{c|}{ Animated } & \multicolumn{2}{c|}{ Iconic } & \multicolumn{3}{|c|}{ F } & \multicolumn{2}{|c|}{ M } \\
\cline { 2 - 10 } & P1 & P2 & P1 & P2 & P1 & P2 & P1 & P2 \\
\hline Tap & 54.2 & 62.5 & 45.8 & 54.2 & 57.1 & 64.3 & 40 & 50 \\
\hline Total & \multicolumn{2}{|c|}{58.3} & \multicolumn{2}{|c|}{50} & \multicolumn{2}{|c|}{60.7} & \multicolumn{2}{|c|}{45} \\
\hline Drag & 100 & 100 & 70.8 & 70.8 & 89.3 & 89.3 & 80 & 80 \\
\hline Total & \multicolumn{2}{|c|}{100} & \multicolumn{2}{|c|}{70.8} & \multicolumn{2}{|c|}{89.3} & \multicolumn{2}{|c|}{80} \\
\hline Scale & 70.83 & 100 & 12.5 & 4.2 & 25 & 42.9 & 65 & 65 \\
\hline Total & \multicolumn{2}{|c|}{85.4} & \multicolumn{2}{|c|}{8.3} & \multicolumn{2}{|c|}{33.9} & \multicolumn{2}{c|}{65} \\
\hline
\end{tabular}

Table 1. Success by language, gender by phase for each task. (P1= Intuitive Phase, P2=Immediate Recall Phase)

The ANOVA revealed significant main effects of the language factor for the drag $[\mathrm{F}(1,48)=21.754, \mathrm{p}<.001]$ and the scale up tasks $[\mathrm{F}(1,48)=120.048, \mathrm{p}<.001]$. No significant main effects were revealed for the tap task $[\mathrm{F}(1,48)=1.594, \mathrm{p}=.214]$. This suggests that using animated hands in dynamic gestures (i.e. those requiring trajectories) is significantly more effective than using a static iconic alternative.

The analysis revealed significant main effects of the phase factor for the scale up task $[\mathrm{F}(1,48)=6.407, \mathrm{p}=.015]$, but not for the tap $[\mathrm{F}(1,48)=0.861, \mathrm{p}=.360]$ or drag tasks $[\mathrm{F}(1,48)=0.246, \mathrm{p}=.360]$. This means that a short training session has only a significant effect on the success rates of the scale up task. Moreover, for this gesture the interaction language*phase was found significant $[\mathrm{F}(1,48)=15.386 \mathrm{p}$ $<001]$, what accounts for how the performance dropped using the Iconic language, in contrast to what happened with the Animated language, which was fully learned by all the participants after only one training session. 
The analysis shows significant main effects of the gender factor for scale up $[\mathrm{F}(1,48)=22.074, \mathrm{p}<.001]$, with males performing more successfully $(65 \%$ vs. $33.9 \%)$. No differences were found for the tap $[\mathrm{F}(1,48)=2.648, \mathrm{p}=$ $.112]$ and the drag gestures $[\mathrm{F}(1,48)=3.791, \mathrm{p}=.059]$.

\section{DISCUSSION AND FUTURE WORK}

In response to RQ1, the results show that the Animated Hand language has a better performance to communicate touch gestures that involve movement of contact points on the surface. This is a valuable result because developmental psychologists such as Levine and Piaget suggested that kids develop spatial reasoning during middle childhood [5]. However, our study suggests that basic reasoning related to the interpretation of moving elements on a surface can be effectively performed during early childhood. On the other hand, differences between languages for the in-place gesture (i.e. tap) were not significant. In fact both languages resulted in equally poor performance because they were unable to convey in an intuitive way the tap operation. In our opinion, this type of reasoning is more complex because it involves a process of classification and association of a visual stimulus to a gesture whose nature cannot be interpreted in terms of spatial analogy with the stimulus. This type of reasoning, as pointed out by Piaget is developed by children at a later stage.

The results obtained after a single training session found that the success improved in general, especially for dynamic gestures, although this improvement was only statistically significant for the scale up operation. Hence, the answer to RQ2 is that a single training session is not enough to learn all the considered gestures being particularly problematic the gestures that do not involve movements on the surface.

Moreover, results showed that tracking several animated hands seems manageable, what responses affirmatively to our RQ3. The scale up task has a 70.83\% success percentage without any previous explanation and reaches $100 \%$ after the learning phase.

In response to our RQ4, about whether gender would make a difference, results showed that the success was only significantly different for the gesture requiring two contact points (i.e. scale up), for which male pre-kindergarten children seem to be more effective than female ones in understanding the required gesture. This is consistent with existing preschool literature on gender differences in visualspatial cognition reviewed by Levine, and colleagues [5]. They found that, on average, preschool boys are more accurate than girls on spatial tasks.

The previous results suggest that designers of direct touch applications for pre-K children should include animated elements to communicate touch gestures that require moving contact points on the surface if children need extra information to proceed. However it remains to be studied more effective mechanisms to communicate static gestures such as tap, double tap and long-pressed. Although these results are promising, there are clear limitations to our work. The experiments involved only one interactive element at a time in the user interface and it remains to be evaluated the effectiveness of animated languages when the interaction area is cluttered with many touchable elements or with elements that may be manipulated with several different gestures. It also remains to be verified whether the inclusion of additional gestures with their corresponding semiotic elements will have an impact on the overall performance because pre-kindergarten children are not able to recall such a variety of different elements.

\section{ACKNOWLEDGMENTS}

Work supported by the MINECO (grant TIN2010-20488) and GVA VALi+d program (grant APOSTD/2013/013).

\section{REFERENCES}

1. Baloian, N., Pino, J. A., and Vargas, R. Tablet gestures as a motivating factor for learning. In Proc. ChileCHI'13, (2013), 98-103.

2. Hofmeester, K., and Wolfe, J. Self-revealing gestures: teaching new touch interactions in windows 8. In ACM CHI EA '12 (2012), 815-828

3. Kähkönen, M. and Ovaska, S. Initial observations on children and online instructions. In Proc. IDC '06, (2006), 93.

4. Lee, R. Gestures. http://gesturecons.com/.

5. Levine, S.C., Huttenlocher, J., Taylor, A., and Langrock, A. Early sex differences in spatial skill. Developmental Psychology, 35, (1999) 940-949.

6. McKnight, L. and Fitton, D. Touch-screen technology for children: Giving the Right Instructions and Getting the Right Responses. In Proc. IDC '10, ACM Press (2010), 238.

7. Nacher, V., Jaen, J., Navarro, E., Catala, A., and González, P. Multi-touch gestures for prekindergarten children. International Journal of Human-Computer Studies. Available online http://dx.doi.org/10.1016/j.ijhcs.2014.08.004

8. Niemi, H. and Ovaska, S. Designing spoken instructions with preschool children. In Proc. IDC '07, (2007), 133.

9. Prates, R.O., de Souza, C.S., and Barbosa, S.D.J. Methods and tools: a method for evaluating the communicability of user interfaces. Interactions 7 , 1 (2000), 31-38.

10. Rideout, V. Zero to Eight: Children's Media Use in America. Common Sense Media, 2011.

11. Walter, R., Bailly, G. and Müller, J. StrikeAPose: Revealing Mid-Air Gestures on Public Displays. In Proc. ACM CHI'13 (2013), 841-850. 